\title{
INFLUENCE OF CARBIDE-PROMOTING ELEMENTS ON THE MICROSTRUCTURE OF HIGH-SILICON DUCTILE IRON
}

\author{
M. Riebisch $(1)$, B. Pustal, and A. Bührig-Polaczek \\ Foundry Institute, RWTH Aachen University, Aachen, Germany
}

Copyright $@ 2020$ The Author(s)

https://doi.org/10.1007/s40962-020-00442-1

\begin{abstract}
Because of its low cost, steel scrap is one of the most important raw materials for the production of ductile iron (DI). The amount of carbide-promoting elements in steel scrap, such as chromium, manganese, molybdenum, niobium and vanadium, is expected to increase in the future. Most of these elements have a negative impact on the microstructure and mechanical properties of DI. The solubility of carbide-promoting elements in solid solutionstrengthened DI materials, standardized in DIN EN 1563:2011, is modified by the high silicon content. For these new materials, the tolerance limits for carbide-promoting elements and their mutual influence must be known to ensure a sustainable production process. To investigate the individual and combined impact of carbide-promoting elements on the carbide content in high-silicon ductile iron EN-GJS-500-14, experimental investigations and

thermodynamic-kinetic microstructure simulations were carried out. Microstructure was characterized using metallographic analysis, and quantitative relations between chemical composition and microstructure were developed by means of regression analysis. Besides this quantitative analysis, it was found that the formation of grain boundary carbides can be detected via thermal analysis. Furthermore, experiments and simulations showed that vanadium promotes the formation of chunky graphite in high-silicon DI castings.

Keywords: high-silicon ductile iron, carbide-promoting elements, pearlite, carbides, graphite morphology, microsegregation, microstructure simulation

\section{Introduction}

Steel scrap is an essential raw material for the production of ductile iron. Modern steels contain an increasing degree of alloying elements to achieve higher strengths. Most of these elements promote the formation of carbides in DI. The trend toward the use of high-strength steels affects the long-term composition of steel scrap available for ductile iron foundries. The increasing concentrations of carbidepromoting elements in steel scrap are a metallurgical challenge for the production of DI. Foundries require detailed knowledge about the individual and combined impact of carbide-promoting elements to decide whether or not a steel scrap is applicable for DI production. Carbides

in DI decrease the materials' ductility and machinability. During the solidification of DI, carbide-promoting elements tend to segregate toward the remaining melt, which leads to carbide precipitation at the grain boundaries. On the contrary, silicon has a strong graphitizing potential and, as shown by Campomanes and Goller, ${ }^{1}$ thus counteracts the carbide-promoting impact of other elements. The new solid solution-strengthened ductile iron grades (SSDI) having silicon contents between 3.2 and $4.3 \mathrm{wt} \%$, according to DIN EN $1563,{ }^{2}$ exhibit a unique combination of strength and ductility. The increased Si content leads to a modified solubility of carbide-promoting elements in austenite. Some carbide-promoting elements can be tolerated in higher amounts compared to conventional DI. ${ }^{3}$
\end{abstract}

This paper is an invited submission to IJMC selected from presentations at the 6th Keith Millis on Ductile Iron held October 23-26, 2018, at the Sonesta Resort, Hilton Head Island, SC. It is published in the IJMC by permission of the DIS (Ductile Iron Society). 


\section{Literature Review}

\section{Impact of Carbide-Promoting Elements in Ductile Iron}

The impact of carbide-promoting elements on the microstructure in ductile iron has been investigated over several decades. Most published experimental work focuses on the individual impact of one or several elements. Rivera et al. analyzed the impact of niobium additions of up to $0.366 \mathrm{wt} \%$ on the microstructure and mechanical properties of DI. ${ }^{4}$ The amount of pearlite increases slightly with increasing $\mathrm{Nb}$ content. Furthermore, the addition of $\mathrm{Nb}$ leads to the formation of polygonal carbides which can be found in both ferrite and pearlite. The effect of $\mathrm{Nb}$ on graphite morphology in DI has been analyzed by Yan et al. for $\mathrm{Nb}$ concentrations of up to $0.69 \mathrm{wt} \%$. $^{5}$ The negative impact of $\mathrm{Nb}$ on graphite morphology leads to a decrease in nodularity and an increase in average nodule diameter. Vanadium also has a negative impact on graphite morphology as investigated by Nechtelberger for $\mathrm{Y}_{\text {II }}$ wedges with section size $25 \mathrm{~mm} .{ }^{6}$ An addition of up to $0.5 \mathrm{wt} \%$ vanadium in DI having $2.1 \mathrm{wt} \%$ silicon increases pearlite by about $30 \%$ and leads to cementite formation when 0.3 $\mathrm{wt} \%$ vanadium is exceeded. The effect of similar vanadium additions in DI possessing 2.6-2.8 wt\% silicon was analyzed by Rezvani et al. in 12-mm-diameter bars. ${ }^{7}$ Here, no cementite formation occurred for vanadium additions of up to $0.54 \mathrm{wt} \%$, while pearlite increases by about $30 \%$ in accordance with the results of Nechtelberger. Also, the area fraction of vanadium carbides at the grain boundaries did not exceed $1 \%$. The effect of chromium, molybdenum and other elements on the microstructure and mechanical properties of heavy-section DI castings was studied by Cho et al. ${ }^{8} \mathrm{Cr}$ is a strong pearlite promoter in DI, which increases tensile strength and decreases elongation. On the contrary, Mo has almost no impact on pearlite percentage. Both elements segregate toward the remaining melt and lead to the formation of grain boundary carbides. The tendency of manganese to promote the formation of intercellular carbides was studied by Ahmadabadi et al. in DI possessing $1 \mathrm{wt} \%$ manganese. ${ }^{9}$ An overview of the individual impact of different alloying elements in DI is given by Hasse. ${ }^{10}$ Extensive experimental investigations are necessary to analyze the cumulative impact of carbidepromoting elements on the microstructure of DI. Campomanes and Goller studied the impact of $\mathrm{Si}, \mathrm{Mn}, \mathrm{Cr}$, Ti and $\mathrm{V}$ by means of a factorial design experiment using a total of 32 alloys. The regression formulas derived from the results indicate that $\mathrm{Si}$ counteracts the impact of the other elements on the pearlite and carbide percentages. Other studies, where regression formulas are generated from experimental results, are reported by various authors. ${ }^{11-13}$ However, a comparable study on the impact of carbidepromoting elements in SSDI is currently lacking. Experiments by Löblich et al. indicate that SSDI tolerates increased amounts of carbide-promoting elements like $\mathrm{Cr}$,
$\mathrm{Mn}$ and $\mathrm{V} .{ }^{14}$ In the present study, the cumulative impact of $\mathrm{Cr}, \mathrm{Mn}, \mathrm{Mo}, \mathrm{Nb}$ and $\mathrm{V}$ on the microstructure of SSDI with $3.8 \mathrm{wt} \%$ silicon is investigated. The aim is to enable a quantitative prediction of pearlite and carbides subject to different cooling conditions.

\section{Solidification Modeling of Ductile Iron}

The volume fraction of carbides formed during the solidification of DI depends on chemical composition and nodule density. The nodule density determines the diffusion distance for carbon and other elements, which, in conjunction with the cooling conditions, significantly influences the number/size of carbides. The diffusion of carbon from the liquid to the graphite nodule through the austenite shell plays an important role during eutectic solidification. A microsegregation model for the solidification of DI was presented by Pustal. ${ }^{15}$ Figure 1 shows the eutectic grain in DI in relation to the representative volume element (RVE) according to the microsegregation model. The magnitude of the RVE adapts to the size of the eutectic grain.

From Figure 1 (right), it can be seen that Si concentration decreases with increasing distance from the graphite nodule, while the concentration of Mo increases. The diffusion of $\mathrm{C}$ through the austenite shell can be impeded by other elements, which can then lead to the formation of chunky graphite (CHG) as shown for nickel in austenitic DI by Pustal et al. ${ }^{16}$ Carbide-promoting elements like Mo and $\mathrm{Nb}$ tend to accumulate in the remaining liquid which, when a critical content of these elements is reached, then leads to carbide formation. Thermodynamic data and transport coefficients are required to simulate the segregation of elements and the kinetic effect of diffusion in the RVE. These data can be obtained from commercial thermodynamic databases, such as "TCFE" ${ }^{17}$

\section{Experimental Procedure}

\section{Design of Experiments}

Near-eutectic solid solution-strengthened ductile iron ENGJS-500-14 possessing an intended silicon content of 3.8 wt $\%$ was alloyed with $\mathrm{Cr}, \mathrm{Mn}, \mathrm{Mo}, \mathrm{Nb}$ and $\mathrm{V}$ according to a factorial design of the experiment. The content of each element was varied in two stages, which led to a total of $2^{5}=32$ experiments. The desired element contents are listed in Table 1. Minimum element contents refer to the chemical composition of the base material without alloyed elements except silicon.

A casting geometry having three different cast parts was used to study the impact of different cooling conditions on graphite morphology, pearlite and carbide area percentage. The casting geometry includes two standardized Y-shaped 


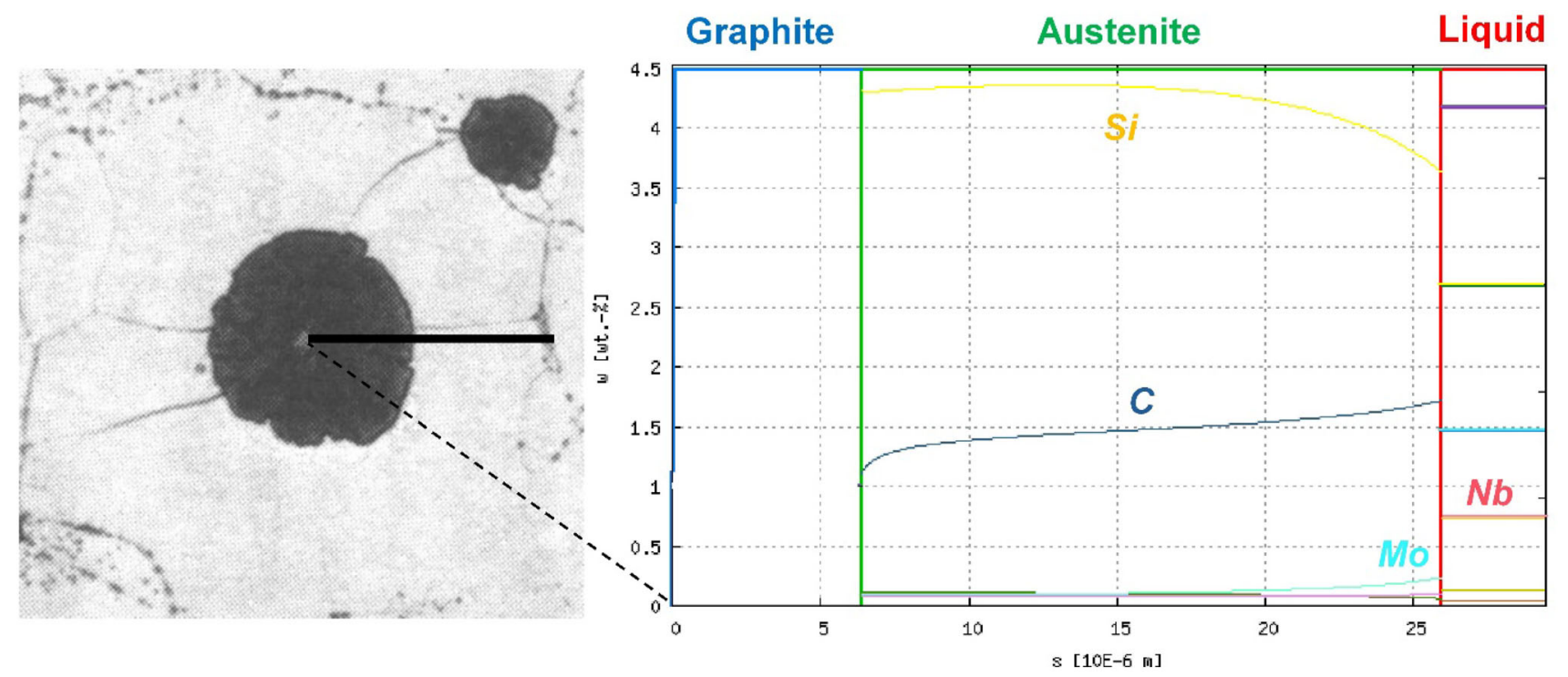

Figure 1. Eutectic grain in ductile iron (left) and representative volume element of the microsegregation model (right).

Table 1. Minimum and Maximum Element Contents for the Factorial Design Experiment

\begin{tabular}{lll}
\hline Element & Min content (wt\%) & Max content (wt\%) \\
\hline $\mathrm{Cr}$ & 0.040 & 0.600 \\
$\mathrm{Mn}$ & 0.170 & 0.500 \\
$\mathrm{Mo}$ & 0.004 & 0.500 \\
$\mathrm{Nb}$ & 0.003 & 0.200 \\
$\mathrm{~V}$ & 0.005 & 0.200 \\
\hline
\end{tabular}

wedges: one of type II and one of type IV, having wall thicknesses 25 and $75 \mathrm{~mm}$, respectively, and a 140-mmdiameter cylindrical cast part. To increase solidification time, an insulating riser sleeve was used to cast the cylindrical part. Cooling curves in the three cast parts were measured via K-type thermocouples, as reported by Riebisch et al. ${ }^{3}$ The solidification time in the three cast parts was approximately 4,15 and $45 \mathrm{~min}$, respectively. Sand molds were produced with furan resin-bonded silica sand.

\section{Casting Procedure}

Recycled cast iron scrap, high-purity iron and ferroalloys were melted in a $50-\mathrm{kg}$ crucible via a medium-frequency induction furnace. Melt was superheated to $1500{ }^{\circ} \mathrm{C}$ $\left(2732{ }^{\circ} \mathrm{F}\right)$ for $10 \mathrm{~min}$, and slag was removed after holding. Magnesium treatment was performed in the crucible using a cerium-free FeSiMg master alloy in a plunging bell. A cerium-free nodularizer was used to avoid the formation of chunky graphite. After nodularization treatment, slag was removed, and the melt was inoculated with $0.2 \mathrm{wt} \%$ of a ferrosilicon-based inoculant $(65 \% \mathrm{Si}, 2 \% \mathrm{Ca}, 1 \% \mathrm{RE}$ and $1 \% \mathrm{Bi}$ ) by stirring into the crucible. The Bi-containing inoculant was used to improve nodularity and prevent the formation of chunky graphite. ${ }^{18} \mathrm{~A}$ small amount of the inoculated melt was removed for thermal analysis in a $35 \times 35 \times 40 \mathrm{~mm}$ sand cup and to produce a chilled sample for spectrometer analysis. The melt was poured into the sand mold at a casting temperature of approximately $1350{ }^{\circ} \mathrm{C}\left(2462{ }^{\circ} \mathrm{F}\right)$. Castings were removed from the sand molds after cooling for $24 \mathrm{~h}$.

\section{Sample Preparation and Analysis}

The three cast parts were cut from the gating system using an angle grinder. Samples for metallographic analysis were taken from the center of each cast part using a water-cooled hollow drill. The embedded samples were progressively ground using silicon carbide paper of different grades (180, 320,500 and 1000) and then polished with diamond polish (9, 3 and $0.25 \mu \mathrm{m}$, respectively) in an automatic buffing machine. Five images of the polished surface of each sample were recorded for graphite shape analysis. The specimen was then etched using $2 \%$ nitric acid in alcohol (Nital) to observe the amount of pearlite in the matrix. After recording five images for pearlite analysis, the specimens were polished again and then etched with Klemm's reagent to observe the grain boundary carbides. Again, five images were recorded. A digital optical microscope having a resolution of $2600 \times 2060$ pixels was used. Magnifications for graphite and pearlite analysis were $100 \times$ for the $\mathrm{Y}_{\mathrm{II}}$ and $\mathrm{Y}_{\mathrm{IV}}$ wedges and $50 \times$ for the cylinder. However, magnification is $200 \times$ for all specimens for the carbide analyses. 
For quantitative image analysis, the image processing software AxioVision KS 400 was used. To determine the nodule count and nodularity, the dimensionless shape factors of roundness and compactness were used for graphite particle classification (class I-VI) according to Velichko and Mücklich. ${ }^{19}$ Classification limits for each class thus depend on the size of the particle according to Velichko. ${ }^{20}$ Nodularity $N$ is calculated by using the following formula:

$N=\frac{\sum_{\mathrm{VI}} A_{i}+\frac{1}{2} \sum_{\mathrm{IV}}^{\mathrm{V}} A_{i}}{\sum_{\mathrm{I}}^{\mathrm{VI}} A_{i}}$.

Eqn. 1

According to Eqn. 1, the area $A$ of all particles of class VI and half of the area of particles of class IV-V are summed together, and the result is divided by the total area of all particles. The total area fraction of graphite $\% G$ was also determined from the polished samples. The total area fraction of graphite and pearlite was determined from the images recorded from the specimens etched with Nital since both phases appear as dark regions and can thus be easily distinguished from ferrite. The area fraction of pearlite $\% P$ was calculated according to Eqn. 2:

$\% P=(\% G+\% P)_{\text {etched }}-\% G_{\text {polished }}$.

Eqn. 2

The area fraction of carbides was determined manually using a digital grid that is laid over the images recorded from the samples etched with Klemm's reagent. The number of grid points located over the carbides was counted to calculate the carbide area fraction.

\section{Modeling and Simulation}

The three cast parts used for experimental carbide analysis show significant differences in the solidification time and cooling rate in the sand mold. The microsegregation model was modified by means of varying the heat extraction rate to reproduce the experimental cooling curves. Figure 2 shows the experimental cooling curves (left), measured via $K$-type thermocouples placed along the space diagonal in the $\mathrm{Y}_{\text {IV }}$ wedge, and simulated cooling curves (right). Very good agreement was obtained between measured and simulated cooling curves. The adopted heat extraction rate and the resulting size of the RVE are listed for every simulated curve. The metallurgical process and the inoculation of the melt determine the nucleus density. The local graphite nodule density develops from a combination of nucleus density and undercooling during eutectic solidification. A statistical nucleation model was implemented in the microsegregation model to calculate nodule density from eutectic undercooling. Experimental data from Petersen and Tiedje ${ }^{21}$ were used to validate the nucleation model. Using the modified microsegregation model, the resulting grain size, and therefore the amount of carbides, can be calculated for a user-defined cooling condition as shown for the cast parts analyzed. Carbide percentages were calculated for all 32 chemical compositions analyzed in the experiments with the $\mathrm{Y}_{\mathrm{II}}$ wedge casting.

\section{Results and Discussion}

\section{Graphite Morphology}

The three different cooling conditions in the analyzed cast parts lead to different graphite size distributions. Figure 3 shows the metallographic images of graphite in the three cast parts. The solidification time has a strong impact on graphite morphology. The nodule count decreases while the size of graphite nodules increases with increasing solidification time. The nodule count is 526, 344 and 136 nodules $/ \mathrm{mm}^{2}$ for the microstructures shown in Figure 3, respectively.

Graphite size and shape are influenced by both the solidification time in the casting and the chemical composition
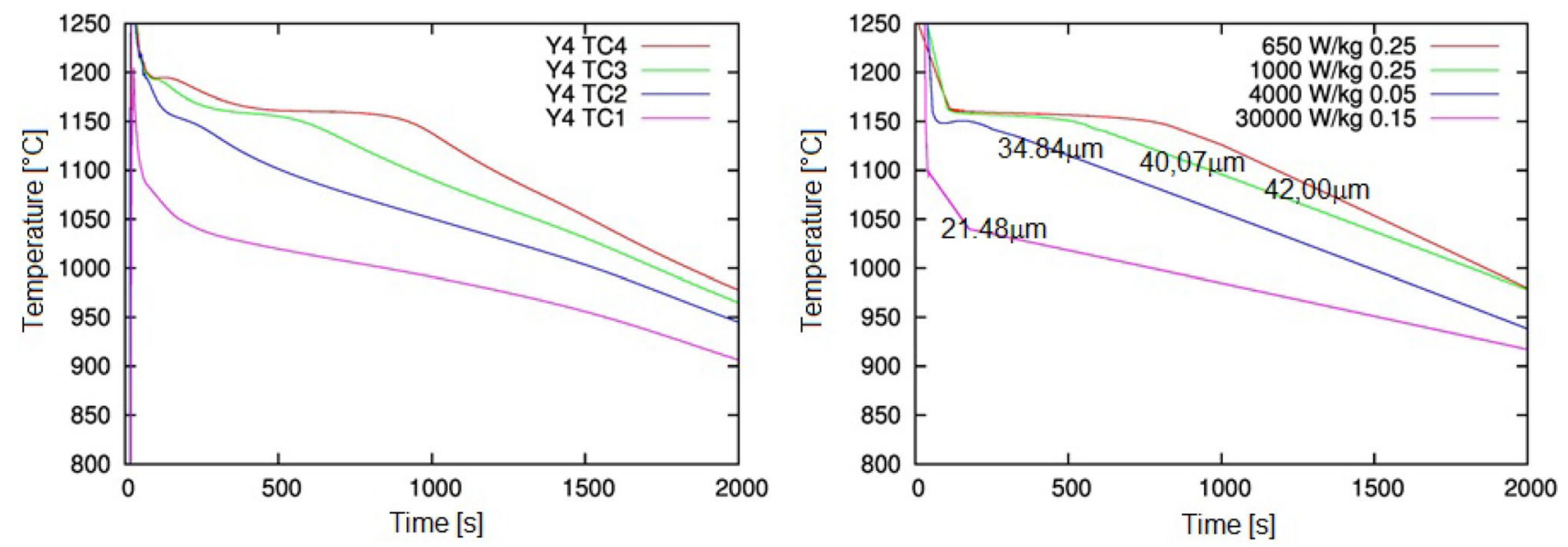

Figure 2. Comparison of measured cooling curves in the $Y_{I V}$ wedge (left) and simulated cooling curves (right). The heat extraction rates $(W / k g)$ applied in the simulations and the resulting RVE size $(\mu \mathrm{m})$ are depicted. 


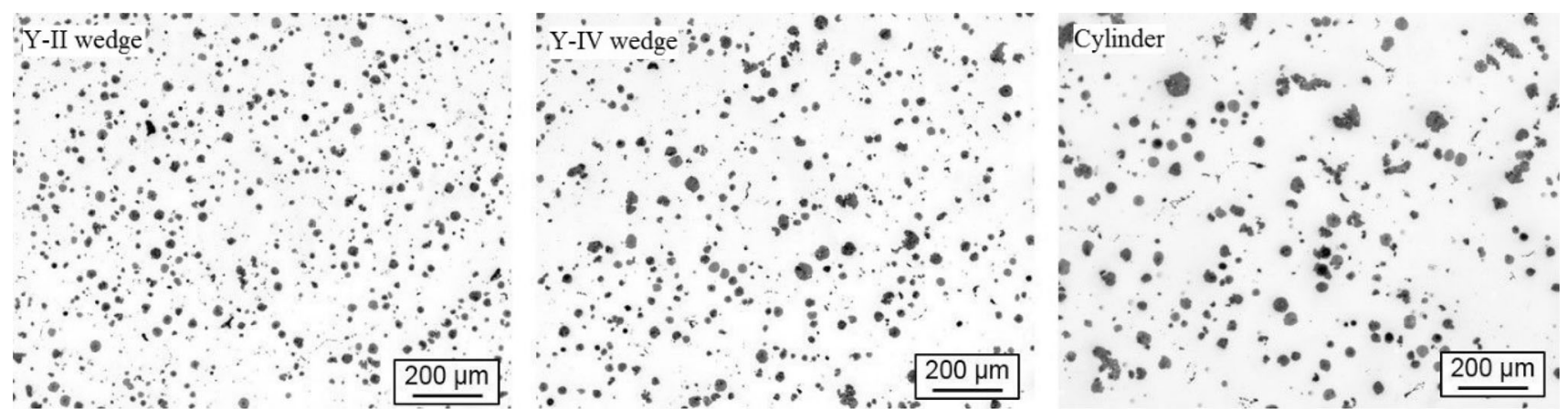

Figure 3. Graphite morphology in the three cast parts.

of the melt. The residual magnesium content following the melt's treatment is responsible for the formation of spheroidal graphite. A minimum residual $\mathrm{Mg}$ content is necessary for an adequate nodularity, as indicated by Shen et al. $^{22}$ However, besides magnesium, many alloying elements influence graphite morphology as shown, for example, by Yan et al. for niobium in ductile iron. ${ }^{5}$ In the present study, it is found that the addition of the analyzed carbide-promoting elements leads to a decrease in nodularity. Figure 4 shows the graphite in the $\mathrm{Y}_{\mathrm{IV}}$ wedge of the base material (a) compared to the alloy possessing molybdenum, niobium and vanadium (b). Nodularity decreases from 82 to $70 \%$ due to the addition of the carbide-promoting elements.

\section{Influence of Carbide-Promoting Elements on Nodularity}

The impact of solidification time and chemical composition on nodularity is quantified by means of a multiple linear regression analysis. Solidification time $\mathrm{t}$, residual $\mathrm{Mg}$ content and the concentration of the five analyzed carbidepromoting elements are considered as independent variables. According to spectrometer analysis, the residual $\mathrm{Mg}$ content in the melt was between 0.027 and $0.043 \mathrm{wt} \%$ and the $\mathrm{S}$ content was below $0.01 \mathrm{wt} \%$ for all casting trials performed. Regression analysis includes the main impact of each variable and first-order interaction terms. The regression formula for nodularity (\%) is

$$
\begin{aligned}
\text { Nodularity }= & 88.3-6.9 * \mathrm{Mn}-13.9 * \mathrm{Cr}-8.2 * \mathrm{Mo} \\
& -13.1 * \mathrm{Nb}-40.9 * \mathrm{~V}+130 * \mathrm{Mg}-0.43 * t . \\
R^{2}= & 74.2 \% .
\end{aligned}
$$

Eqn. 3

Solidification time $t$ is in minutes, and element concentrations are in wt $\%$. Equation 4 indicates that all carbide-promoting elements, in particular vanadium, have a negative impact on nodularity. A comparison of the calculated and measured nodularity is shown in Figure 5. The dotted line indicates an ideal correlation between calculation and measurement. The mean variation of data is due to other parameters affecting nodularity, such as casting temperature and superheating, which are not included in the regression analysis.

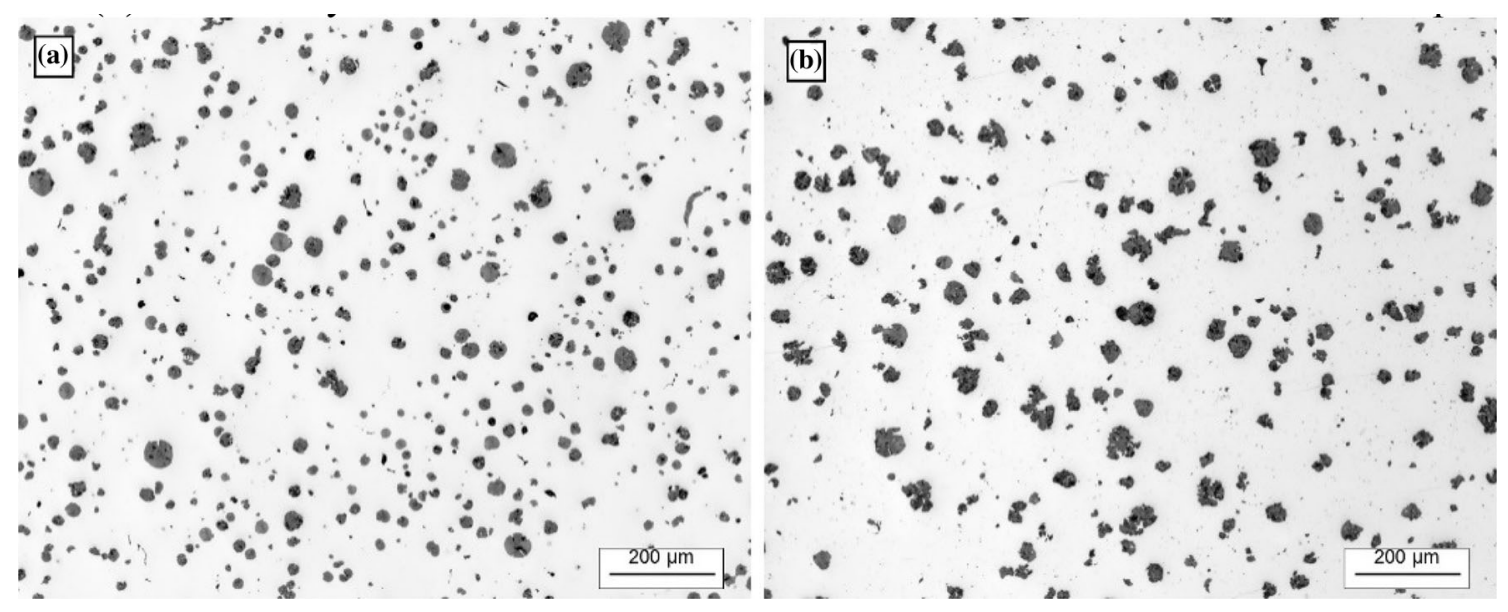

Figure 4. Comparison of graphite morphology in the $Y_{I V}$ wedge for (a) $M g=0.027$ wt\% and no additional elements, to (b) $\mathrm{Mg}=0.031 \mathrm{wt} \%$ and addition of $\mathrm{Mo}=0.474 \mathrm{wt} \%, \mathrm{Nb}=0.196 \mathrm{wt} \%$ and $V=0.175 w t \%$. 


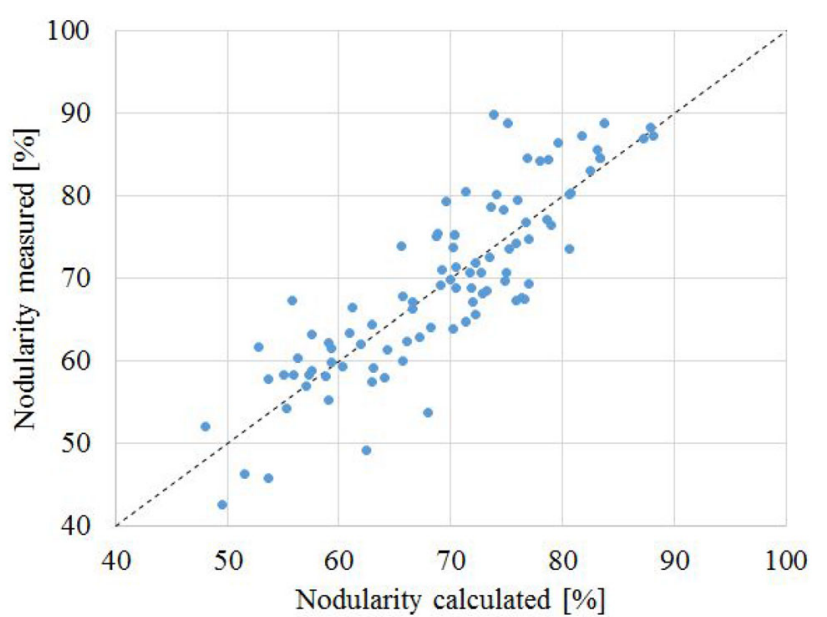

Figure 5. Correlation between calculated and measured nodularity.

\section{Impact of Vanadium on Graphite Morphology}

The distinct negative impact of $\mathrm{V}$ on graphite nodularity, according to Eqn. 4, indicates that vanadium influences solidification kinetics in SSDI, in particular the growth of graphite nodules. During the solidification of DI, graphite nodules are surrounded by austenitic shells, and further growth of graphite occurs by diffusion of $\mathrm{C}$ through the austenite shell. When the diffusive flux of carbon toward the graphite nodules is impeded by the presence of certain alloying elements, the competing kinetics of chunky graphite (CHG) growth exceeds the spheroidal graphite growth, as shown for austenitic DI by Pustal et al. ${ }^{16}$ Further experimental investigations with vanadium additions of up to $0.5 \mathrm{wt} \%$ confirm that $\mathrm{V}$ promotes the formation of $\mathrm{CHG}$ in large SSDI castings. Figure 6 (right) shows a significant amount of CHG morphology in the cylindrical casting containing $0.5 \mathrm{wt} \%$ vanadium. According to the microsegregation model, the presence of vanadium in austenite reduces the diffusive flux of $\mathrm{C}$ and thus increases the carbon concentration gradient which is necessary for the further growth of spheroidal graphite, as depicted in Figure 6 (left).

The kinetic disadvantage for spheroidal graphite growth and the thermodynamic conditions for nucleation of graphite at the austenite-liquid interface are decisive factors for developing a CHG morphology. The addition of 0.5 wt $\%$ vanadium increases solidification time by about $5 \mathrm{~min}$ and decreases solidification temperature by about $15 \mathrm{~K}$ compared to pure SSDI. These conditions lead to the kinetic preference for $\mathrm{CHG}$ growth.

\section{Pearlite Area Percentage}

Most carbide-promoting elements in ductile iron tend to increase the amount of pearlite in the as-cast microstructure. According to Lacaze et al., ${ }^{23}$ chromium and manganese decrease the eutectoid equilibrium temperature $T_{\alpha}$ at which austenite decomposes into ferrite and graphite. This leads to a decrease in the carbon diffusion coefficient during the ferritic reaction and thus promotes the formation of pearlite. In the present study, it is found that $\mathrm{Cr}$ and $\mathrm{Mn}$ have the highest impact on pearlite area fraction in SSDI. The impact of manganese on the pearlite area fraction is shown in Figure 7. Pearlite appears as dark regions when the microstructure is etched using Nital.

The impact of carbide-promoting elements on pearlite area fraction is quantified via linear regression analysis. It is
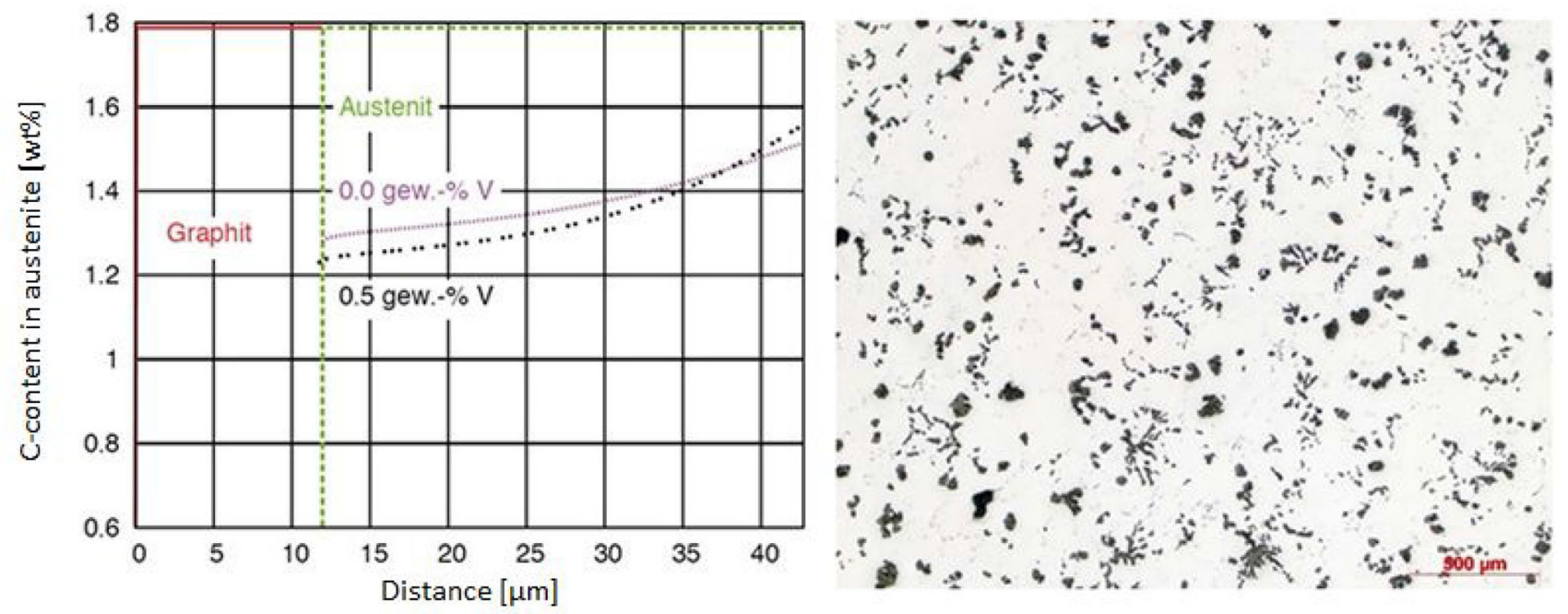

Figure 6. Increase in $C$ concentration gradient in austenite possessing addition of $V$ (left) and CHG in the cylindrical cast part having addition of $0.5 \mathrm{wt} \% \mathrm{~V}$ (right). 


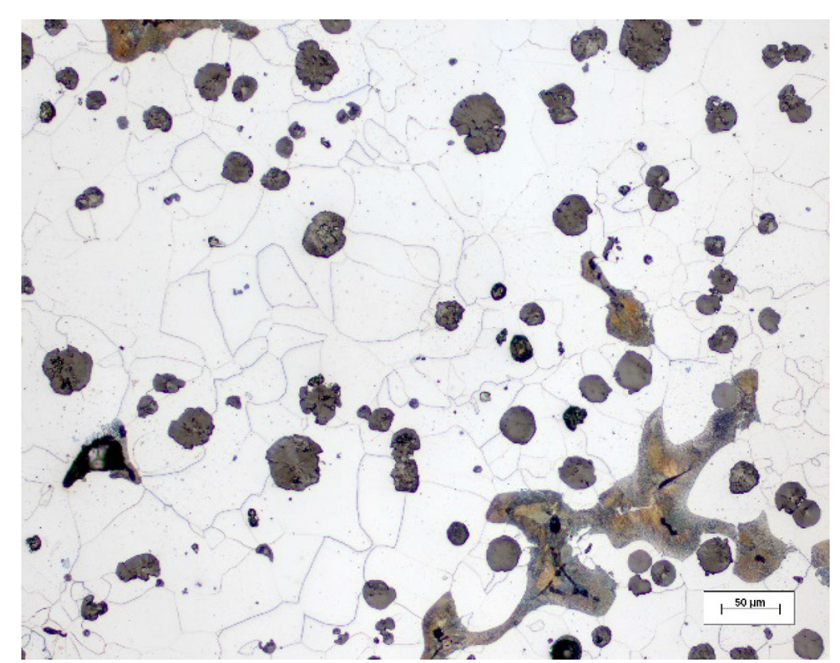

Figure 7. A metallographic image of 5 area\% pearlite in the $Y_{I V}$ wedge, alloyed with 0.5 wt $\%$ manganese.

found that the different cooling conditions analyzed have no significant impact on pearlite area fraction. The regression formula for pearlite area fraction in SSDI is

$$
\begin{aligned}
\text { Pearlite }= & 73.6 * \mathrm{Cr}+27.8 * \mathrm{Mn}+5.8 * \mathrm{Mo} \\
& +8.2 * \mathrm{Nb}+17.0 * \mathrm{~V}-8.8 . \\
R^{2}= & 91.9 \% .
\end{aligned}
$$

Eqn. 4

A very good correlation is found for the experimental pearlite area fraction as a function of chemical composition. In Figure 8, the calculated and experimental pearlite fractions are compared. At first sight, the nonexistent impact of the cooling conditions on the amount of pearlite is surprising since the cooling conditions analyzed have a significant impact on nodule count and thus on the diffusion distance for carbon during eutectoid transformation. However, the lower nodule count is combined with a lower cooling rate during eutectoid transformation and the associated increased time for

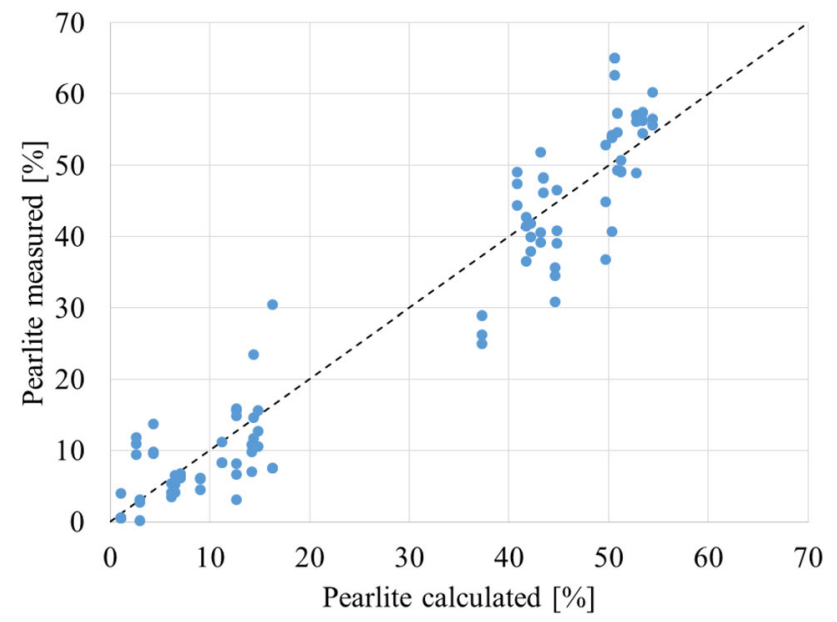

Figure 8. Correlation between calculated and measured pearlite area fraction. diffusive transport of carbon from austenite to graphite through the ferritic shell that forms around the graphite nodules. It is supposed that these two effects counteract each other subject to the cooling conditions analyzed.

\section{Carbide Area Percentage}

The area fraction of carbides in the microstructure depends on chemical composition and the segregation of carbidepromoting elements toward the remaining liquid during eutectic solidification. The cooling conditions analyzed have a strong impact on nodule density and thus on the diffusion distance for carbon and other elements during solidification and cooling in the solid state. A lower nodule count leads to more pronounced segregation of elements and increases the area fraction of carbides which form at the end of solidification. In the present study, the carbide area percentage found in the cast parts' microstructure increases with increasing solidification time for almost all chemical compositions analyzed. Figure 9 shows carbides in the cylindrical cast part alloyed with manganese, chromium and vanadium. The carbides are found at grain boundaries, which appear bright in contrast to the matrix due to the applied etching method. Figure 9 indicates that different types of carbides form in the microstructure when several elements are added to the melt. The formation of mixed carbide structures plays an important role with regard to the total carbide area percentage.

\section{Impact of Chemical Composition and Solidification Time on Carbide Area Percentage}

The impact of factors affecting the formation of carbides is quantified via multiple regression analysis. The

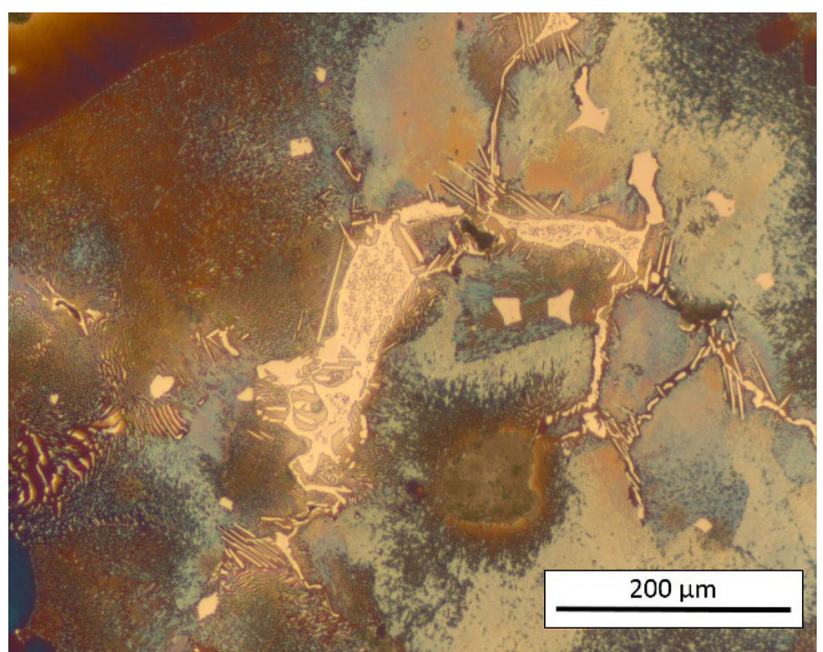

Figure 9. A metallographic image of carbides in the cylindrical casting alloyed with $\mathrm{Cr}, \mathrm{Mn}$ and $\mathrm{V}$. 
solidification time $\mathrm{t}$ and the concentration of $\mathrm{Cr}$, Mn, Mo, $\mathrm{Nb}$ and $\mathrm{V}$ are considered as independent variables. The interaction between several carbide-forming elements, as indicated in the previous section, is considered by adding interaction terms into the regression formula with the intention of improving the degree of correlation. Interaction terms, in the form of products of two independent variables, are added stepwise until the correlation coefficient reaches its maximum. The resulting regression formula for carbide area percentage is thus

$$
\begin{aligned}
\text { Carbide }= & -0.065+0.79 * \mathrm{Mo}+1.21 * \mathrm{Nb} \\
& +5.41 * \log (t) * \mathrm{Nb} * \mathrm{~V}+2.44 * \log (t) * \mathrm{Cr} * \mathrm{Mo} \\
& +8.06 * \log (t) * \mathrm{Cr} * \mathrm{~V}+2.35 * \log (t) * \mathrm{Cr} * \mathrm{Mn} \\
& -3.85 * \log (t) * \mathrm{Cr} * \mathrm{Mn} * \mathrm{Mo} \\
& -16,76 * \log (t) * \mathrm{Cr} * \mathrm{Mn} * \mathrm{~V} . \\
R^{2} & =73.3 \% .
\end{aligned}
$$

Eqn. 5

Only $\mathrm{Mo}$ and $\mathrm{Nb}$ appear as main effect terms in the equation, while all other variables only appear in multiple interaction terms. The solidification time appears in the logarithmic form since this leads to a better correlation factor. However, the resulting $R^{2}$ is considerably lower compared to pearlite regression analysis. The interaction terms in Eqn. 5 represent the existence of mixed carbides and their impact on the total carbide area percentage. Chromium forms mixed carbides with all other elements analyzed, except niobium. The formation of mixed carbides leads to a disproportionately high increase in carbide percentage. According to Eqn. 5, all mixed carbide structures are detected via EDX measurements on samples having the respective chemical composition. Calculated and measured carbide percentages are shown in Figure 10 for all 32 casting trials analyzed.

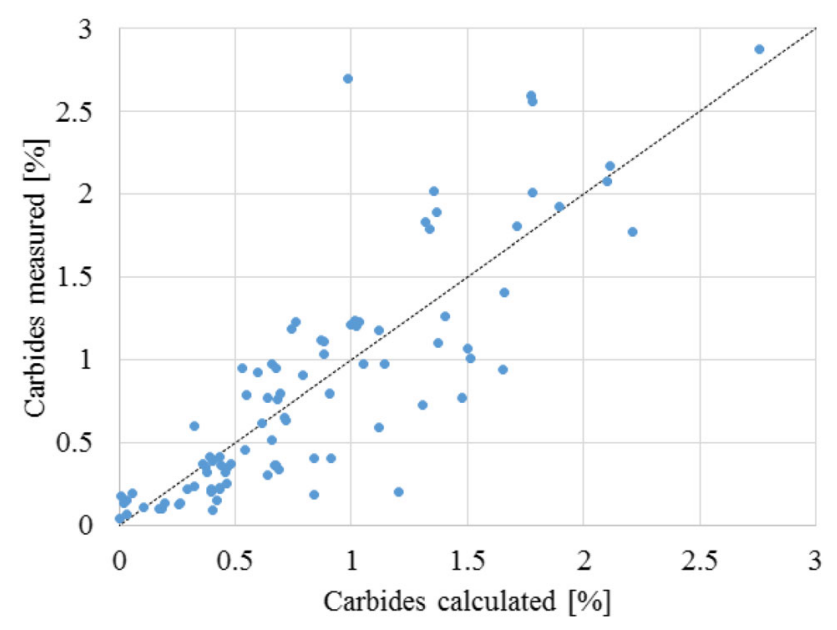

Figure 10. Correlation between calculated and measured carbide area percentage.

\section{Detection of Carbide Formation via Thermal Analysis}

The presence of carbide-promoting elements in the melt influences solidification and thus leads to changes in the cooling curves recorded during thermal analysis. According to Doepp and Schwenkel, ${ }^{24}$ most alloying elements like chromium or molybdenum cause a shift of the eutectic equilibrium temperatures of the iron-graphite and iron-cementite system. The eutectic temperature TEC of the metastable system determined via thermal analysis can be expressed as a function of chemical composition by means of regression analysis. This leads to the following regression formula:

$$
\begin{aligned}
\mathrm{TEC}\left[{ }^{\circ} \mathrm{C}\right]= & 1083+10.5 * \mathrm{Mn}+8.1 * \mathrm{Cr} \\
& -8.4 * \mathrm{Mo}-8.2 * \mathrm{Nb}+7.0 * \mathrm{~V} . \\
R^{2}= & 88 \% .
\end{aligned}
$$

The metastable eutectic equilibrium temperature thus increases with increasing concentration of $\mathrm{Cr}, \mathrm{Mn}$ and $\mathrm{V}$ and decreases when $\mathrm{Mo}$ and $\mathrm{Nb}$ are added. $\mathrm{Si}$ is not included in Eqn. 6 because it was at a constant level of approximately $3.8 \mathrm{wt} \%$ in all experiments. According to Eqn. 6, the quantitative results for $\mathrm{Cr}, \mathrm{Mn}$ and $\mathrm{Mo}$ are in good agreement with the scientific literature. ${ }^{24}$ Nevertheless, the calculation of TEC from the chemical composition is not suitable to predict the percentage of carbides in the microstructure since the analyzed cast parts predominantly solidify according to the stable iron-graphite system. With the exception of niobium carbides, the carbides analyzed in the present study form at the end of eutectic solidification. The $\mathrm{Nb}$ carbides are precipitated from the melt at an early stage of solidification. The end of solidification (EOS), detected via thermal analysis, can thus be used as an indicator of the formation of grain boundary carbides when niobium is not present in the melt. The EOS is indicated by an inflection point in the cooling curve. At that point, the precipitation of carbides from the remaining melt at the end of solidification changes the cooling rate since austenite and carbides differ in latent heat and growth velocity. By comparing the cooling rate $\left({ }^{\circ} \mathrm{C} / \mathrm{s}\right)$ at the end of solidification with the carbide percentage in the $\mathrm{Y}_{\mathrm{II}}$ wedge, the following regression formula is determined:

$$
\begin{aligned}
\text { Carbide }\left(\mathrm{Y}_{\text {II }}\right) & =45.377 * e^{-2.004 * \text { Cooling rate }} \\
R^{2} & =75.3 \% .
\end{aligned}
$$

According to Eqn. 7, an exponential dependence exists between the cooling rate at the end of solidification and the resulting carbide percentage. Figure 11 graphically depicts the dependency of carbide area percentage on the cooling rate at EOS. The exponential regression curve is indicated by a dotted line.

For the ductile iron alloy without additional carbide-promoting elements, $\mathrm{dT} / \mathrm{dt}$ at EOS is below $-4{ }^{\circ} \mathrm{C} / \mathrm{s}$ which indicates 


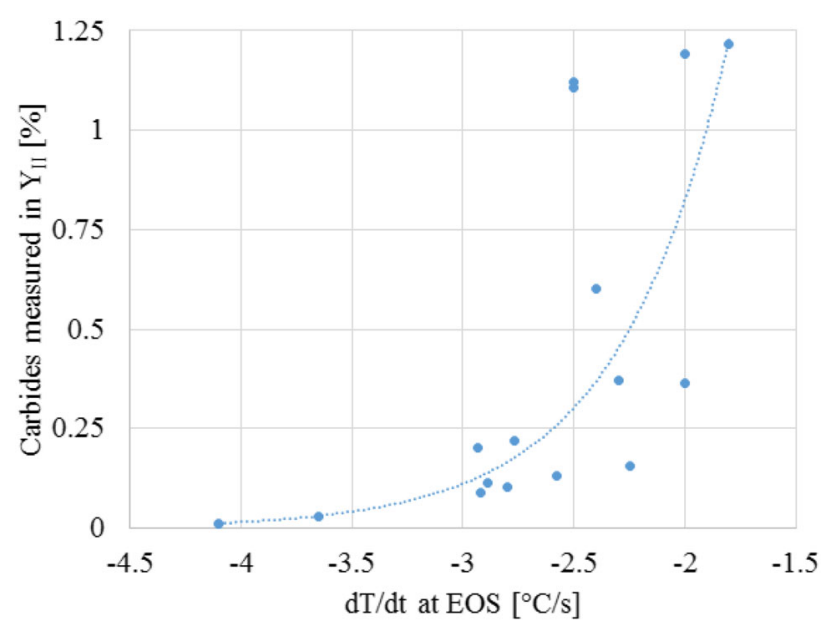

Figure 11. Exponential dependency between cooling rate at EOS in the TA sample and carbides in the $Y_{I I}$ wedge casting.

an abrupt end of eutectic solidification. No carbides are found in the $\mathrm{Y}_{\mathrm{II}}$ wedge of this alloy. Cooling decelerates when more carbides are formed at the end of solidification. Compared to the prediction of carbides from the chemical composition (Eqn. 5), the correlation factor is slightly improved.

\section{Comparison of Experimental and Simulated Carbide Area Percentages}

The resulting carbide percentage according to the microsegregation model depends on chemical composition, cooling conditions and the thermodynamic data used for simulation. In the present study, the thermodynamic database "TCFE6" is used ${ }^{17}$ to predict carbide fraction in the $\mathrm{Y}_{\text {II }}$ wedge casting. In Figure 12, the simulated carbide percentages for 15 selected alloys in the $\mathrm{Y}_{\mathrm{II}}$ wedge are compared with the experimental results.

By comparing experimental and simulated carbide area percentages, it is noticeable that the individual impact of the five alloying elements is either under- or overestimated by the microsegregation model. The simulated carbide area

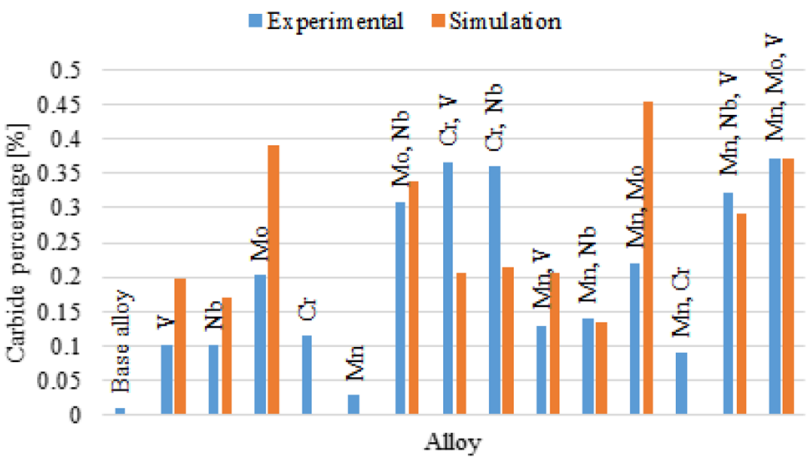

Figure 12. Experimental and simulated carbide percentage for 15 alloys. percentage for $\mathrm{Mo}, \mathrm{Nb}$ and $\mathrm{V}$ is nearly twice that of the experimental result. On the contrary, according to the simulation $\mathrm{Cr}$ and $\mathrm{Mn}$ do not lead to the precipitation of any carbides, although carbides were experimentally found for these alloys. Cr promotes carbide formation by segregating toward the final areas to solidify, which increases the $\mathrm{Fe}-\mathrm{Fe}_{3} \mathrm{C}$ eutectic temperature in the remaining melt. ${ }^{10}$ According to the simulation, the solidification is completed prior to the temperature falling below the $\mathrm{Fe}-\mathrm{Fe}_{3} \mathrm{C}$ eutectic temperature. The simulation results are very sensitive to the solubility of the carbide-promoting elements in austenite. It is possible that the solubilities of $\mathrm{Mo}, \mathrm{Nb}$ and $\mathrm{V}$ are underestimated by the thermodynamic database used which increases the resulting carbide percentage. However, experimental and simulated results are in good agreement for some of the alloys with two or three added elements.

\section{Conclusions}

The influence of carbide-promoting elements on graphite morphology, fraction of pearlite and fraction of carbides in high-silicon ductile iron with $3.8 \mathrm{wt} \% \mathrm{Si}$ was studied by means of experimental analysis and microstructure simulations. It was shown that the elements analyzed have a negative impact on spheroidal graphite growth and promote both the formation of carbides during eutectic solidification and pearlite during eutectoid transformation. Vanadium has a significant, negative impact on graphite morphology and promotes the formation of chunky graphite in castings with long solidification times. It was shown by means of microsegregation simulations that vanadium decelerates the diffusion of carbon in austenite. This leads to the kinetic preference of chunky graphite growth. Thus, the impact of vanadium on graphite morphology is similar to the influence on nickel in austenitic DI. ${ }^{16}$ Pearlite area fraction can be described as a linear function of chemical composition by means of multiple linear regression. In the present study, the correlation factor $R^{2}=91.1 \%$ indicates a very good agreement between measured data and regression. The different cooling conditions analyzed do not have a significant influence on pearlite fraction. The interaction between several carbide-promoting elements and the solidification time have a significant impact on the amount of carbides in the microstructure. This is described by the regression formula Eqn. 5. Furthermore, the formation of grain boundary carbides can be detected via thermal analysis. Experimental and simulated carbide area percentages often differ considerably. The results of microsegregation simulation suggest that carbide formation is very sensitive to the solubility of the elements in austenite.

\section{Acknowledgements}

Open Access funding provided by Projekt DEAL. The presented results are derived from IGF Project $18555 \mathrm{~N}$ 
of the "FVG Research Association of the Foundry Industry." This project was funded within the scope of the joint collaboration program IGF by the Federal Ministry for Economic Affairs and Energy, following a decision by the German Bundestag. The authors gratefully acknowledge the Georg Fischer GmbH in Mettmann and ASK Chemicals for the supply of the raw materials and master alloy for ductile iron production. Furthermore, the authors thank Quarzwerke GmbH for the supply of silica sand and Hüttenes Albertus Chemische Werke GmbH for the supply of resin bonders for the manufacture of molds.

Open Access This article is licensed under a Creative Commons Attribution 4.0 International License, which permits use, sharing, adaptation, distribution and reproduction in any medium or format, as long as you give appropriate credit to the original author(s) and the source, provide a link to the Creative Commons licence, and indicate if changes were made. The images or other third party material in this article are included in the article's Creative Commons licence, unless indicated otherwise in a credit line to the material. If material is not included in the article's Creative Commons licence and your intended use is not permitted by statutory regulation or exceeds the permitted use, you will need to obtain permission directly from the copyright holder. To view a copy of this licence, visit http://creativecommons.org/licenses/by/4.0/.

\section{REFERENCES}

1. E. Campomanes, R. Goller, The effect of certain carbide promoting elements on the microstructure of ductile iron. AFS Trans. 87, 619-626 (1979)

2. DIN, Gießereiwesen - Gusseisen mit Kugelgraphit, Deutsche Fassung EN 1563:2011, 2012

3. M. Riebisch, H. Groß, B. Pustal, A. Bührig-Polaczek, Influence of carbide-promoting elements on the pearlite content and the tensile properties of high silicon SSDI ductile iron. Int. J. Metalcast. 12(1), 106-112 (2018)

4. I. Rivera, A. Roca, F. Patino, M. Cruells, Microalloyed niobium influence on ductile ferrite cast iron. Int. J. Cast Met. Res. 16, 65-70 (2003)

5. Y. Yan, L. Chang, X. Chen, Q. Hua, Q. Zhai, Effect of niobium on the morphology of nodular graphite in ductile iron. Adv. Mater. Res. 852, 163-167 (2014)

6. E. Nechtelberger, Der Einfluss von Vanadium auf das Gefüge und die mechanischen Eigenschaften von Gußeisen mit Kugelgraphit, Gießerei-Praxis 1 (1969)

7. M. Rezvani, R.A. Harding, J. Campbell, The effect of vanadium in as-cast ductile iron. Int. J. Cast Met. Res. 10, 1-15 (1997)

8. G.S. Cho, K.H. Choe, K.W. Lee, A. Ikenaga, Effects of alloying elements on the microstructures and mechanical properties of heavy section ductile cast iron. J. Mater. Sci. Technol. 23, 97-101 (2007)

9. M. Nili Ahmadabadi, E. Niyama, E. Tanino, T. Abe, T. Ohide, Chemical composition and structural identification of eutectic carbide in 1 Pct Mn ductile iron. Metall. Mater. Trans. A 25A, 911-918 (1994)
10. S. Hasse, Niedriglegiertes Gusseisen mit Kugelgraphit. Gießerei-Praxis 8, 293-301 (2005)

11. T. Thielemann, Zur Wirkung von Spurenelementen im Gusseisen mit Kugelgraphit. Gießereitechnik 16(1), 16-24 (1970)

12. D. Venugopalan, A. Alagarsamy, Einfluss von Legierungszusätzen auf die Gefüge und die mechanischen Eigenschaften von technischen Gußeisen mit Kugelgraphit. Gießerei-Praxis 3, 21-28 (1992)

13. G. Wolf, W. Stets, U. Petzschmann, Bewertung der kumulativen Wirkung von Carbid bildenden Elementen auf die Eigenschaften von GJS-400-15. Gießerei 10, 24-32 (2011)

14. H. Löblich, W. Stets, G. Gassner, P. Schumacher, Hoch siliciumhaltiges Gusseisen mit Kugelgraphit toleriert größere Anteile an carbidbildenden Elementen. Giesserei 99(4), 28-32 (2012)

15. B. Pustal, Solidification modeling of austenitic cast iron: a holistic approach (Fakultät für Georessourcen und Materialtechnik, RWTH, Aachen, 2010)

16. B. Pustal, A. Bührig-Polaczek, Physico-chemical causes of the formation of chunky graphite in austenitic ductile iron. Acta Mater. 124, 137-142 (2017)

17. Thermo-Calc Software AB

18. W. Stets, H. Löblich, G. Gassner, P. Schumacher, Solution strengthened ferritic ductile cast iron properties, production and application. Int. J. Metalcast. 8(2), 35-40 (2014)

19. A. Velichko, F. Mücklich, Neue Möglichkeiten der objektiven Graphitklassifizierung in Gusseisen durch Nano-Tomographie und internetbasierte Online-Verfahren. VDI-Berichte 2007, 21-36 (1949)

20. A. Velichko, Quantitative $3 D$ Characterization of Graphite Morphologies in Cast Iron using FIB Microstructure Tomography (NaturwissenschaftlichTechnische Fakultät III Chemie, Pharmazie, Bio- und Werkstoffwissenschaften, Universität des Saarlandes, Saarbrücken, 2008)

21. K.M. Pedersen, N. Tiedje, Solidification of hypereutectic thin wall ductile cast iron. Mater. Sci. Forum 508, 63-68 (2006)

22. Z. Shen, H. Zheng, T. Li, Y. Xu, R. Xu, X. Tian, The influence of the residual $\mathrm{Mg}$ content in the ductile cast iron on the formation law of spheroidal graphite. Adv. Mater. Res. 415-417, 907-914 (2011)

23. J. Lacaze, J. Sertucha, L.M. Aberg, Microstructure of As-cast ferritic-pearlitic nodular cast irons. ISIJ Int. 56(9), 1606-1615 (2016)

24. R. Doepp, S. Schwenkel, Contribution to the influence of chemical composition and cooling conditions on the eutectic solidification range of $\mathrm{Fe}-\mathrm{C}-\mathrm{X}$-melts. Mater. Sci. Eng. A 413-414, 334-338 (2005)

Publisher's Note Springer Nature remains neutral with regard to jurisdictional claims in published maps and institutional affiliations. 